\title{
Conditioned taste aversion in the Mongolian gerbil (Meriones unguiculatus)
}

\author{
ROBIN B. KANAREK, KIMBERLEY S. ADAMS, and JEAN MAYER \\ Department of Nutrition, Harvard School of Public Health, Boston, Massachusetts 02115
}

\begin{abstract}
The development of a conditioned taste aversion to a novel food was examined in the Mongolian gerbil. Ingestion of an orange-flavored sucrose solution was followed by intraperitoneal injections of $3 \mathrm{ml} / 100 \mathrm{~g}$ body weight $.15 \mathrm{M} \mathrm{LiCl}, 4 \mathrm{ml} / 100 \mathrm{~g}$ body weight $.15 \mathrm{M} \mathrm{LiCl}$, or $3 \mathrm{ml} / 100 \mathrm{~g}$ body weight physiological saline. Two-bottle preference tests between the sucrose solution and water showed that LiCl-injected animals had developed an aversion to the sucrose solution, consuming a significantly smaller percentage of the solution than saline-injected animals. The aversion was maintained for at least 2 weeks following the injection of $\mathrm{LiCl}$. The results extend the conditioned taste aversion phenomenon to another species and stress the importance of this type of learning in the survival of the animal in its natural habitat.
\end{abstract}

Animals develop conditioned taste aversions to novel foods when the ingestion of the food is followed by sickness induced by the administration of a toxic agent (for reviews see Garcia, Hankins, \& Rusiniak, 1974; Rozin \& Kalat, 1971). While research on conditioned taste aversions has predominantly employed the rat as experimental subject, the phenomenon has been shown to occur in a variety of species including Atlantic cod (Mackay, 1974), chicken (Capretta \& Moore, 1970), quail (Wilcoxon, Dragoin, \& Kral, 1971), guinea pig (Braveman, 1974), and coyote (Gustavson, Garcia, Hankins, \& Rusiniak, 1974).

A species which recently has become widely used in behavioral and physiological research is the Mongolian gerbil (Meriones unguiculatus) (Gulotta, 1971; Rich, 1968; Robinson, 1974). With respect to its feeding behavior, the gerbil both in its natural habitat and in the laboratory has been reported to be eclectic in its tastes, consuming a wide range of foods including grasses, fruits, vegetables, seeds, and standard laboratory animal diets (Bannikov, 1954; Robinson, 1974). Like rats, gerbils prefer sucrose solutions to water. Both in two-bottle preference tests and in single-bottle 24-h intakes, gerbils consume a larger percentage of sucrose than water (Laughlin, Donovick, \& Burright, 1972).

To compare the feeding behavior of the gerbil to other species with respect to its ability to develop conditioned taste aversions, the present experiment examined the effect of lithium chloride ( $\mathrm{LiCl}$ )-induced sickness on the gerbils' consumption of a preferred sucrose solution.

George H. Collier sponsors this paper and takes full editorial responsibility for its content. This study was supported by Grant NS 01941 from the National Institutes of Health and by the Fund for Research and Teaching, Department of Nutrition, Harvard University.

\section{METHOD}

\section{Animals and Apparatus}

Twelve male gerbils weighing between 47.0 and $53.0 \mathrm{~g}$ and 12 female gerbils weighing between 40.0 and $46.5 \mathrm{~g}$ were used. The gerbils were purchased from Tumblebrook Farms, West Brookfield, Massachusetts. All animals were housed individually in standard cages of steel and hardware cloth $(18.7 \times 25.3 \times 17.5 \mathrm{~cm})$. Food was ground Purina Laboratory Chow. Tap water and the test solution were provided in inverted $250-\mathrm{ml}$ glass water bottles with stainless steel drinking spouts. The experimental room was maintained at $22 \pm 2{ }^{\circ} \mathrm{C}$, and on a 12-h-light/12-h-dark cy cle (light onset: 8:00 a.m.).

\section{Procedure}

All animals were given 7 days to adapt to the caging regime. On Days 8 and 9 , body weight and food and water intakes were recorded to provide baseline measures with which to compare intakes following the injection of $\mathrm{LiCl}$. On Days 10,11, and 12, the gerbils were food-and water-deprived for $221 / 2 \mathrm{~h}$. Following the deprivation periods on Days 10 and 11, food and water were provided for $1 \frac{1 / 2}{h}$, and intakes were measured. On the basis of body weight, measured after the second $11 / 2 \mathrm{~h}$ of access to food and water, three groups of four females and four males each were formed. The mean body weight of each of the three groups was $46.1 \mathrm{~g}$. On Day 12 following deprivation, the animals were given $1 \frac{1 / 2-h}{}$ access to a $5 \%$ sucrose solution flavored with $.25 \mathrm{ml}$ orange extract (Durkee, Cleveland, Ohio) per $100 \mathrm{ml}$ solution. Immediately following the removal of the sucrose solution, all animals in Group 1 received an intraperitoneal injection of $4 \mathrm{ml} / 100 \mathrm{~g}$ body weight $.15 \mathrm{M} \mathrm{LiCl}$, Group 2 received $3 \mathrm{ml} / 100 \mathrm{~g}$ body weight $.15 \mathrm{M} \mathrm{LiCl}$, and Group 3 received $3 \mathrm{ml} / 100 \mathrm{~g}$ body weight physiological saline. Food and water were returned for the following $24 \mathrm{~h}$. On Days 14 and 15, access to food and water was again limited to $1 \frac{1}{2} \mathrm{~h}$ per day. On Day 16 , the orange-flavored solution was provided for $1 \frac{1 / 2}{h}$, and each group was injected with either $\mathrm{LiCl}$ or saline as on Day 12. Following injections, all animals were given ad-lib access to food and water.

To examine the development of the conditioned taste aversion to the flavored sucrose solution, two-bottle preference tests between the sucrose solution and water were given on Days 19 and 20 . Sucrose and water intakes were measured at the end of each 24-h period. Food was continuously available during the testing periods. Following 10 days of ad-lib access to food and water, a third two-bottle preference test was conducted on Day 31 . 


\section{RESULTS AND DISCUSSION}

Male and female gerbils responded similarly to all experimental treatments. Following the injection of $\mathrm{LiCl}$ or saline, none of the animals displayed any overt signs of illness. Food and water intakes measured in the 24-h periods after the injections were not significantly different among the three groups.

Figure 1 presents the mean percentage of the flavored sucrose solution consumed by each group for each of the three 24-h two-bottle preference tests. Analysis of variance performed for each 24-h test revealed significant differences among the three groups (Test 1: $\mathrm{F}=57.69, \quad \mathrm{df}=2 / 21, \mathrm{p}<.01 ; \quad$ Test $2: \quad \mathrm{F}=108.46$, $\mathrm{df}=2 / 21, \quad \mathrm{p}<.01 ; \quad$ Test $3: \quad \mathrm{F}=168.70, \quad \mathrm{df}=2 / 21$, $\mathrm{p}<.01)$. A posteriori comparisons between the groups using Scheffe's method showed that while the saline-injected group consumed a larger percentage of the sucrose solution than either of the LiCl-injected groups, the percentage of sucrose consumed was not significantly different between the $\mathrm{LiCl}$-injected groups.

Table 1 shows the absolute amount of sucrose and water consumed by each group during each 24-h two-bottle test. With respect to the saline control animals, both of the groups injected with $\mathrm{LiCl}$ consumed less sucrose and more water. In comparison with intakes during the baseline period on Days 8 and 9, water intakes were less for the saline-injected group and greater for the LiCl-injected groups during the preference tests.

No significant differences in sucrose or water consumption were found for any group when the data were analyzed across the three preference tests.

The results of the present experiment extend the generality of the conditioned taste aversion phenomenon to another species, the Mongolian gerbil. Gerbils injected with $\mathrm{LiCl}$ following the consumption of a novel fluid displayed as strong an aversion to the novel solution 2 weeks after injection as 3 days following injection. Tests made after the present experiment was completed showed that $\mathrm{LiCl}$-injected gerbils given access to the flavored sucrose solution as long as 5 weeks after injection still displayed an aversion to the solution. In contrast to the results of experiments using rats, which have shown that the more severe the illness (i.e., the higher the dose of $\mathrm{LiCl}$ ), the stronger the aversion of the

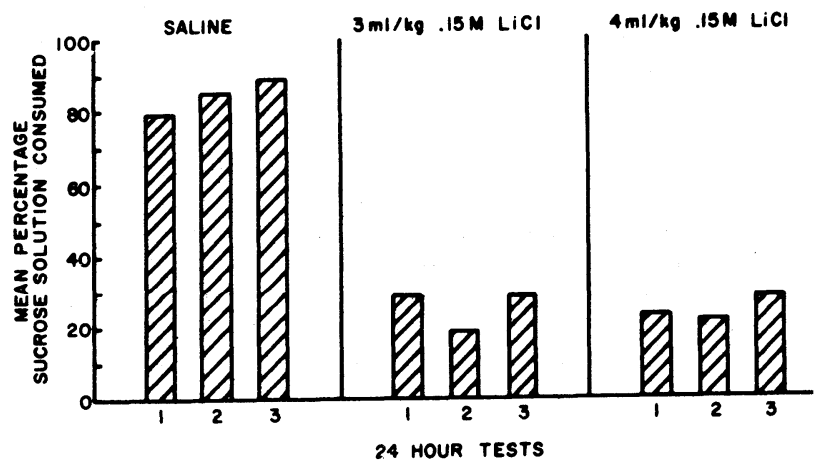

Figure 1. Mean percentage of sucrose solution consumed in each of the three 24-h two-bottle preference tests by each group.
Table 1

Total Amount of Flavored Sucrose Solution and Water Consumed by Each Animal During Each 24-h Two-Bottle Preference Test

\begin{tabular}{|c|c|c|c|c|c|c|}
\hline \multirow{2}{*}{$\begin{array}{l}\text { Subject } \\
\text { Number }\end{array}$} & \multicolumn{2}{|c|}{ Test 1} & \multicolumn{2}{|c|}{ Test 2} & \multicolumn{2}{|c|}{ Test 3} \\
\hline & $S$ & W & $S$ & W & $\mathrm{S}$ & W \\
\hline
\end{tabular}

\begin{tabular}{crlrlll}
\hline Saline & & & & & & \\
1 & 23 & 4 & 25 & 3 & 34 & 2 \\
2 & 14 & 3 & 23 & 2 & 30 & 6 \\
3 & 3 & 6 & 6 & 5 & 14 & 4 \\
4 & 38 & 3 & 39 & 1 & 28 & 1 \\
5 & 32 & 5 & 40 & 2 & 41 & 2 \\
6 & 18 & 3 & 22 & 1 & 28 & 5 \\
7 & 33 & 5 & 43 & 4 & 41 & 2 \\
8 & 21 & 4 & 21 & 5 & 24 & 1 \\
Mean & 22.8 & 4.1 & 27.4 & 2.8 & 30.0 & 2.8
\end{tabular}

$3 \mathrm{ml} / 100 \mathrm{~g}, .15 \mathrm{M} \mathrm{LiCl}$

$\begin{array}{ccccccc}1 & 4 & 9 & 3 & 9 & 4 & 9 \\ 2 & 3 & 7 & 2 & 7 & 4 & 9 \\ 3 & 4 & 8 & 2 & 7 & 4 & 9 \\ 4 & 4 & 11 & 3 & 12 & 3 & 11 \\ 5 & 6 & 16 & 3 & 10 & 4 & 10 \\ 6 & 5 & 16 & 3 & 11 & 3 & 26 \\ 7 & 6 & 10 & 5 & 9 & 5 & 11 \\ 8 & 4 & 12 & 3 & 10 & 5 & 11 \\ \text { Mean } & 4.5 & 11.1 & 3.0 & 9.4 & 4.0 & 12.0\end{array}$

$4 \mathrm{ml} / 100 \mathrm{~g}, .15 \mathrm{M} \mathrm{LiCl}$

\begin{tabular}{ccccccc}
1 & 3 & 8 & 4 & 7 & 5 & 9 \\
2 & 3 & 11 & 3 & 9 & 4 & 12 \\
3 & 3 & 10 & 2 & 7 & 3 & 10 \\
4 & 2 & 9 & 1 & 10 & 4 & 8 \\
5 & 4 & 13 & 3 & 13 & 4 & 14 \\
6 & 4 & 12 & 3 & 10 & 4 & 20 \\
7 & 5 & 11 & 3 & 9 & 6 & 12 \\
8 & 3 & 13 & 2 & 12 & 4 & 13 \\
Mean & 3.4 & 10.8 & 2.6 & 9.6 & 4.2 & 12.2 \\
\hline
\end{tabular}

Note. $S=$ sucrose, $W=$ water.

taste paired with illness (Garcia et al., 1974), no significant differences were found between gerbils given $3 \mathrm{ml} / 100 \mathrm{~g}$ or $4 \mathrm{ml} / 100 \mathrm{~g}$ body weight $.15 \mathrm{M} \mathrm{LiCl}$. As the gerbil responded similarly to the rat in all other aspects of this experiment, it is possible that the gradation between dose levels was not sufficient to produce significant differences in the degree of illness produced in the gerbils. To test this possibility, we are presently examining the effect of using a wider range of $\mathrm{LiCl}$ doses in the development of conditioned taste aversions in the gerbil. The generality of the conditioned taste aversion phenomenon across species stresses the importance of this type of learning for the survival of the animal. Without the ability to learn which foods are beneficial and which harmful, survival in the natural environment would be made exceptionally difficult.

\section{REFERENCES}

Bannikov, A. G. Mammals of the Mongolian Peoples' Republic. Report Mongolian Comm. 53. Academy of Science, U.S.S.R., Moscow, 1954 (Translated by Dr. Douglas Lay).

Braveman, N. S. Poison-based avoidance learning with flavored or coloured water in guinea pigs. Learning and Motivation, 1974, 5, 182-194. 
Capretta, P. J., \& Moore, M. J. Appropriateness of reinforcement to cue in the conditioning of food aversions in chickens (Gallus gallus). Journal of Comparative \& Physiological Psychology, 1970, 72, 85-89.

Garcia, J., Hankins, W. G., \& Rusiniak, K. W. Behavioral regulation of the milieu interne in man and rat. Science, 1974, 185, 824-831.

Gullota, E. F. Merione unguiculatus. Mammalian Species, 1971, 3, $1-5$.

Gustavson, C. R., Garcia, J., Hankins, W. G., \& Rusiniak, K. W. Coyote predation control by aversive conditioning. Science, 1974, 184, 581-583.

Laughlin, M. E., Donovick, P. J., \& Burright, R. G. Consummatory behavior in meadow voles (Microtus pennsylvanicus) and gerbils (Meriones unguiculatus). American Zoologist, 1972, 12, 656-657.
MACKAY, B. Conditioned food aversion produced to toxicosis in Atlantic cod. Behaviorat Biology, 1974, 12, 347-355.

Rich, S. T. The Mongolian gerbil (Meriones unguiculatus) in research. Laboratory Animal Care, 1968, 18, 235-243.

RoBinson, D. Care and maintenance of the Mongolian gerbil. A technician's manual. West Brookfield, Mass: Tumblebrook Farms, 1974.

Rozin, P., \& Kalat, J. W. Specific hungers and poison avoidance as adaptive specializations of learning. Psychological Review, 1971, 78, 459-486.

Wilcoxon, H. C., Dragoin, W. B., \& Kral, P. A. Illness induced aversions in rat and quail: Relative salience of visual and gustatory cues. Science, 1971, 171, 826-828.

(Received for publication June 11, 1975.) 